\title{
Activation of cellular immunity and marked inhibition of liver cancer in a mouse model following gene therapy and tumor expression of GM-SCF, IL-21, and Rae-1
}

Mingrong Cheng ${ }^{1,2^{*}+}$, Kangkang Zhi ${ }^{{ }^{\dagger \dagger}}$, Xiaoyan $\mathrm{GaO}^{4 \dagger}$, Bing $\mathrm{He}^{5^{*}}$, Yingchun $\mathrm{Li}^{2}$, Jiang Han ${ }^{1}$, Zhiping Zhang ${ }^{1}$ and Yan $\mathrm{Wu}^{1}$

\begin{abstract}
Background: Cancer is both a systemic and a genetic disease. The pathogenesis of cancer might be related to dampened immunity. Host immunity recognizes nascent malignant cells - a process referred to as immune surveillance. Augmenting immune surveillance and suppressing immune escape are crucial in tumor immunotherapy.
\end{abstract}

Methods: A recombinant plasmid capable of co-expressing granulocyte-macrophage colony- stimulating factor (GM-SCF), interleukin-21 (IL-21), and retinoic acid early transcription factor-1 (Rae-1) was constructed, and its effects determined in a mouse model of subcutaneous liver cancer. Serum specimens were assayed for IL-2 and INF- $\gamma$ by ELISA. Liver cancer specimens were isolated for Rae-1 expression by RT-PCR and Western blot, and splenocytes were analyzed by flow cytometry.

Results: The recombinant plasmid inhibited the growth of liver cancer and prolonged survival of tumor-loaded mice. Activation of host immunity might have contributed to this effect by promoting increased numbers and cytotoxicity of natural killer (NK) cells and cytotoxic T lymphocytes (CTL) following expression of GM-SCF, IL-21, and Rae-1. By contrast, the frequency of regulatory T cells was decreased, Consequently, activated CTL and NK cells enhanced their secretion of INF- $\gamma$, which promoted cytotoxicity of NK cells and CTL. Moreover, active CTL showed dramatic secretion of IL-2, which stimulates CTL. The recombinant expression plasmid also augmented Rae-1 expression by liver cancer cells. Rae-1 receptor expressing CTL and NK cells removed liver cancer.

Conclusions: The recombinant expression plasmid inhibited liver cancer by a mechanism that involved activation of cell-mediated immunity and Rae-1 in liver cancer.

Keywords: Gene therapy, Natural killer cells, Cytotoxic T lymphocytes, Liver cancer, Immune escape, Cell-mediated immunity

\footnotetext{
* Correspondence: cmrlq@126.com; 2011cmr@sina.com

${ }^{\dagger}$ Equal contributors

${ }^{1}$ Department of General Surgery, Pudong New Area District Zhoupu Hospital,

Shanghai 201318, China

${ }^{5}$ Department of General Surgery, Shanghai Fifth People's Hospital, Fudan

University, Shanghai 200240, China

Full list of author information is available at the end of the article
} 


\section{Introduction}

In the 1950s, Burnet proposed that the immune system could recognize nascent malignant transformed cells in a process known today as immune surveillance [1]. Antitumor immunity to aberrant self-antigen (tumor antigen) is prioritized in cellular immunity, and requires the interplay of a variety of accessory and major effector cells including CD8+ and CD4+ T cells [2,3]. When tumor cells fail to express an antigenic epitope, defects might occur in antigen processing, modulation, or tumor antigen loss. There might also be a lack of major histocompatibility complex class I (MHC- I) expression, functional co-stimulatory molecule expression, inhibition of tumor cell expression, and tumor cell expression of apoptotic regulatory ligands. In addition, there could be general immunodeficiency and immunosuppression of natural killer (NK) cell and cytotoxic T cell (CTL) activity. Collectively. each of these pathways could promote immune escape of the tumor target [4-6]. Therefore, cancer cells attempt to use multiple mechanisms to escape recognition by and attack by host immunity to promote their survival and proliferative capability. However, immune escape can be avoided in one of two ways. Firstly host immunity could be stimulated, especially in the context of anti-tumor CTL and NK cells. Secondly the expression of antibodies or ligands that are recognized by host immunity in cancer cells might be augmented, and examples of this include natural killer group 2D (NKG2D).

NKG2D is a C-type lectin-like activating receptor that is present on the surface of NK cells with a stressinducible ligand of MHC- I class molecules A/B (MIC A/B) [7]. The retinoic acid early transcription factor-1 (Rae-1) is one of the most frequently studied mouse NKG2D ligands. Rae-1 is detected in many mouse cancer cells. Similar to MICA and MICB ligands of NKG2D in the human immune system, Rae- 1 is highly expressed under stressful environments (e.g., in response to heat shock, ultraviolet light, virus infection, malignant transformation, and exposure to carcinogenic substances). The affinity of Rae-1 for NKG2D is tens or hundreds of times greater than that of the killer inhibitory receptor (KIR) [8]. Rae-1 is not expressed in normal cells but is restricted to expression by epithelial cancer cells. Expression of Rae-1 is combined with NKG2D and mediated by the DAP10 pathway (the "self-induction hypothesis"), making cancer cell expression of Rae-1 easily identified by immune cells and hence removal of cancer cells that express it [9]. Thus NK and CD8 + T cells are capable of removing cancer cells that highly express NKG2D ligands [10]. In vitro experiments showed that induced expression of NKG2D ligands following transfection of cancer cells and antibody blocking significantly enhance tumor cell susceptibility to NK cells. Perhaps of greater relevance is the observation that subcutaneous injection of cancer cells containing the transfected NKG2D gene in mice induces potent tumoricidal immune responses and significant dampening of tumor cell growth [10]. Consequently, immune cells easily identify tumor cells that highly express Rae-1.

Others have shown that gene expression of both GMCSF and IL-21 can significantly inhibit tumors and activate host immunity including CTL and NK cell activation $[11,12]$. Previously, we studied recombinant plasmids that expressed both GM-CSF and IL-21 in a mouse model of orthotopic liver cancer by intravenous tail vein injection [13]. This construct markedly blocked the growth of tumors and enhanced both NK cell and CTL activity.

The current study focuses on stimulating either cellmediated immune activation including CTL and NK cells [14], or enhancing the expression of molecules like Rae-1 that are expressed by tumor cells and subsequently identified by host immunity [15]. Few reports have shown the effects of attempting to simultaneously increase immune activation and the molecules identified by immune surveying cells. In this study, we propose an immune escape inhibitory system that is based on the immune escape hypothesis and our previously published work.

\section{Materials and methods}

\section{Reagents and instruments}

Methyl Thiazolyl Tetrazolium (MTT) was obtained from Sigma Ltd, Shanghai, China. Plasmid maxi preparation kits were obtained from Promega (Beijing) Biotech Co., Ltd., Beijing, China. Interferon (IFN- $\gamma$ ), interleukin-2 (IL-2), and enzyme-linked immunosorbent assay (ELISA) kits were obtained from Santa Cruz Biotechnology, Santa Cruz, CA, USA. Fluorescent-labeled antibodies of fluorescein isothiocyanate (FITC)-anti-mouse CD3, PEanti-mouse CD4, PE-anti mouse CD8, FITC-anti-mouse CD25, Alexa 647-anti mouse Foxp3, FITC-anti-mouse CD11b, and PE-anti-mouse CD27 were provided by BD Bioscience, San Jose, CA, USA.

\section{Mice and cell-lines}

Balb/c mice (male, 7 wk old, weighing $20 \mathrm{~g}$, and specific pathogen free (SPF)) were obtained from the Animal Center of Fudang University (Shanghai, China). Hepatic cancer cells (H22) were provided by the China Center for Type Culture Collection (CCTCC, Wuhan, China). The target cell-line YAC-1 of natural killer (NK) cell origin was routinely cultured in the immunology laboratory of Shanghai Fudan University. The selected culture medium was RPMI 1640 and was obtained from the Sigma Chemical Company. The ethics committee of Shanghai Zhoupu Hospital (Shanghai, China) and Fudan University approved the mouse model experiments described in this report. 


\section{Construction of the recombinant plasmid of pGM-CSF-GFP -IRES-IL-21-Rae-1}

The genes for both GM-CSF and IL-21 were obtained from the spleens of mice. Rae-1 and GFP were chemically synthesized. The polymerase chain reaction (PCR) primers were designed and synthesized according to the genetic coding sequence (CDS) for both GM-CSF and IL-21 (Table 1). The enzyme cleavage sites targeted by Xhol and EcoRI were added to the $5^{\prime}$ and $3^{\prime}$ ends of the GM-CSF gene, respectively. EcoRI and MluI cleavage sites were added to the $5^{\prime}$ and $3^{\prime}$ ends of the GFP gene, respectively. Xba1 and Sal1 cleavage sites were added to the $5^{\prime}$ and $3^{\prime}$ end of the Rae-1 gene, respectively. Sal1 and Not1 cleavage sites were added to the $5^{\prime}$ and $3^{\prime}$ ends of the IL-21 gene, respectively. GFP segmentation was connected with a destination vector pIRES, forming a plasmid pGFP-IRES, which was added to the GM-CSF gene to form a vector referred to as pGM-CSF-GFPIRES, followed by insertion of the PCR products of the Rae-1 gene to obtain a new vector referred to as pGMCSF-GFP-IRES-Rae-1. The IL-21 digested segments were inserted to form the pGM-CSF-GFP-IRES-Rae-1 expression construct, to form a eukaryotic expression vector referred to as pGM-CSF-GFP-IRES-Rae-1-IL-21. In the process, GM-CSF-GFP was used for MCS A and Rae-1IL-21 was used for MCS B.

\section{A mouse model of subcutaneous liver cancer}

The hepatic cancer cell-line H22 was adoptively transferred into mice to construct a mouse model of subcutaneous liver cancer. The mice were sacrificed to harvest their tumor tissues. Fresh tumors with vigorous growth were selected and prepared as a tumor singlecell suspension (at a density of $6 \times 10^{7}$ cells $\mathrm{mL}^{-1}$ ). The suspension $(50 \mu \mathrm{L})$ was injected into the armpit of the right forelimb of experimental mice using a $1 \mathrm{~mL}$ syringe.

Table 1 Showing the primer sequences used to amplify the genes for GM-CSF, GFP, Rae-1, and IL-21

\begin{tabular}{ll}
\hline Genes & Primers \\
\hline GM-CSF-Xhol-F & CAGATCTCGAGGCCACCATGTGGCTGCAGAATTTACTTTC \\
GM-CSF-ECoRI-R & GTCAGAATTCCCATTITGGCCTGGTIITTG \\
GFP-ECoRI-F & GTCAGAATTCATGGTGAGCAAGGGCGAG \\
GFP-Mlul-R & ACTTAACGCGTTACTTGTACAGCTCGTCCATGC \\
Rae-1-Xba1-F & GTACATTCTAGAGCCACCATGAGTCTGTTGGATCAACCTCT \\
Rae-1-Sal1-R & GAATGTCGACGTATTTCTTATTCCTTGGCTTTAGCT \\
IL-21-Sal1-F & GTCAGTCGACGCCACCATGGAGAGGACCCTTGTCTGTC \\
IL-21-Not1-R & AATTGCGGCCGCCTAGGAGAGATGCTGATGAATCATC \\
\hline
\end{tabular}

Note: Italics indicates the enzyme cleavage sites for Xhol and EcoRI, EcoRI and Mlul, Xba1and Sal1, and Sal1and Not1.

\section{Recombinant plasmid treatment in a mouse model of subcutaneous liver cancer}

On the 5th day after the mouse model was established, mice were randomly divided into six groups of 10 mice per group including control, IRES/GFP, IRES/IL-21, IRES/GM-SCF, IRES/GM-SCF-IL-21 and IRES/combination. In the control group, mice were injected with $200 \mu \mathrm{L}$ phosphate buffered saline (PBS). Additionally, $200 \mu \mathrm{L}$ PBS containing $100 \mu \mathrm{g}$ of the recombinant plasmid was injected to the mouse tumors of each group (IRES/GF, IRES/IL-21, IRES/GM-SCF, IRES/GM-SCF-IL21 and IRES/combination). The injection was repeated once a day for five continuous days. After ten days, the mice in each group were sacrificed by overdosing of the anesthesic agents. The liver cancer tissues of each mouse in each group were separated from the mouse by a conventional technique and made into specimens suitable for determination of their weights and volumes. Tumor volumes were calculated by the formula: Tumor volume $\left(\mathrm{cm}^{3}\right)=0.523 \times \mathrm{L} \times \mathrm{W}^{2}$. Here, $\mathrm{L}(\mathrm{cm})$ and $\mathrm{W}(\mathrm{cm})$ indicated the length and width of the tumors respectively as measured by a Vernier caliper. Gene and protein expression of GFP, Rae-1, GM-SCF and IL-21 were then detected in the tumor tissues by RT-PCR and Western blot analysis of each group. The remaining experimental models of 13 mice per group were used for survival analysis.

\section{ELISA detection of IL-2 and INF- $\gamma$}

Mouse serum specimens were isolated in each group and kept at $-20^{\circ} \mathrm{C}$ for determination of IL- 2 and INF- $\gamma$ content. For ELISA detection, serum specimens were thawed at $37^{\circ} \mathrm{C}$ in an incubator, followed by dilution with double distilled water to $500 \mu \mathrm{L}$. Meanwhile, the IL- 2 and INF- $\gamma$ standards were diluted to $8000 \mu \mathrm{g} \mathrm{L}^{-1}$. In a 96-well microtiter plate, each well then received $150 \mu \mathrm{L}$ diluted specimens, and then $50 \mu \mathrm{L}$ standards or specimens were added for $15 \mathrm{~min}$. They were oscillated evenly and incubated for $2 \mathrm{~h}$ at room temperature. The liquid in the wells was removed and the wells washed with $400 \mu \mathrm{L}$ of detergent-containing buffer four times, followed by the addition of horseradish peroxidaseconjugated IL-2 and INF- $\gamma(200 \mu \mathrm{L})$, then oscillated evenly, and incubated for $2 \mathrm{~h}$ at room temperature. Next, the liquid was removed and washed with $400 \mu \mathrm{L}$ detergent-containing bugger four times. An equal amount of developer A and B were evenly mixed, which were added with $200 \mu \mathrm{L}$ of the enzyme labeled antibody, and then incubated at room temperature in the dark for $30 \mathrm{~min}$. Next, $50 \mu \mathrm{L}$ of stop buffer was added to complete the enzyme reaction. The specimens were immediately detected using spectrophotometry by measuring its optical density at a wavelength of $450 \mathrm{~nm}$. Samples and standards were run in triplicate, and the sensitivity of 
the assays was determined to be 0.1 units $/ \mathrm{mL}$ for both IL-2 and INF- $\gamma$.

\section{Reverse transcription-polymerase chain reaction (RT-PCR)} Total cellular RNA was determined by the Trizol method. The reverse transcription was conducted using $1 \mu \mathrm{L}$ RNA and $0.5 \mu \mathrm{L}$ AMV reverse transcriptase, $2.5 \mu \mathrm{L}$ cDNA as a template for PCR amplification, $0.1 \mu \mathrm{L}$ polymerase Ex Taq HS, $0.1 \mu \mathrm{L}$ sense primer and $0.1 \mu \mathrm{L}$ antisense primer. The reaction conditions were: $94^{\circ} \mathrm{C}$ initial denaturation for $2 \mathrm{~min}, 94^{\circ} \mathrm{C}$ denaturation for $40 \mathrm{~s}, 50$ $65^{\circ} \mathrm{C}$ annealing for $40 \mathrm{~s}, 72^{\circ} \mathrm{C}$ extension for $1 \mathrm{~min}$, and a total of 35 cycles, and $72^{\circ} \mathrm{C}$ extension for 5 min for one cycle. The PCR products were kept frozen at $-20^{\circ} \mathrm{C}$. The glyceraldehyde-phosphate dehydrogenase (GAPDH) gene was used as an internal housekeeping control and amplified as described above. The shRNA target fragments and $6 \mu \mathrm{L}$ of the PCR products of the internal control GAPDH were separated on a $2 \%$ agarose gel and by electrophoresis at $120 \mathrm{~V}$ and $100 \mathrm{~mA}$ for $30 \mathrm{~min}$. After electrophoresis, the gel was placed in ethidium bromide (EB) staining solution for $5 \mathrm{~min}$. The positive PCR reactions showed clear amplification segments as expected. Quantity-One software (Bio-Rad Laboratories Inc, Hercules, CA, USA) was used for analysis of electrophoresis data, and gray-scale scanning. By comparison against the gray values of GAPDH, we obtained relative values of the mRNA products in the sample target genes.

\section{Western blot analysis of relative protein expression}

The extraction was performed in order to harvest sufficient proteins for $12 \% \mathrm{w} / \mathrm{v}$ sodium lauryl sulfate polyacrylamide gel electrophoresis (SDS-PAGE). Before placing samples on the separating gel, proteins underwent electrophoresis at $80 \mathrm{~V}$ and then at $120 \mathrm{~V}$ until its front was about $1 \mathrm{~cm}$ from the bottom of the gel. Polyvinylidene fluoride fibre (PVDF) membranes were immersed in methanol for $5 \mathrm{~min}$, then transferred to a buffer solution (pH 8.3, $25 \mathrm{mmol} \mathrm{L}^{-1}$ Tris- $\mathrm{HCl}, 192 \mathrm{mmol} \mathrm{L}^{-1}$ glycine, and $20 \%$ methanol) for $10 \mathrm{~min}$ at room temperature. Proteins were transferred onto PVDF membranes at $100 \mathrm{~V}$ for $70 \mathrm{~min}$, and then blocked with $5 \%$ bovine serum albumin/PBS by incubating the membrane overnight at $4^{\circ} \mathrm{C}$, and then reacting the membrane with diluted primary antibodies (1:2000) for $3 \mathrm{~min}$ at room temperature, rinsing in $0.05 \%$ PBS-Tween 20 three times for $10 \mathrm{~min}$ each. Membranes were then reacted with diluted secondary antibodies (1:8000) for $3 \mathrm{~h}$ targeted against the membrane-bound protein-primary antibody complexes with rinsing in $0.05 \%$ PBS-Tween 20 three times for 10 min each, followed by detection in ECL reagent. Equal parts of solutions A and B in the ECL kit were mixed, and reacted with the membrane for $1 \mathrm{~min}$. Proteins were developed and photographed by a gel imaging system. The film scanning of the protein was performed using an Image J version 1.44 software program to obtain average density values (ADV). The relative absorbance value was calculated as a ratio of ADV and GAPDA.

\section{Flow cytometry}

Mice spleens were harvested, carefully ground, and filtered against mesh screens to obtain single-cell suspensions, which were incubated in RPMI 1640. Cells were seeded into a 96-well microtiter plate, followed by centrifugation at $300 \mathrm{~g}$ for $5 \mathrm{~min}$. Then, cell pellets were retained and washed 2-3 times with $200 \mu \mathrm{L}$ of PBS. The washed cells were mixed with a blocking agent and incubated under gentle shaking at $4^{\circ} \mathrm{C}$ for $60 \mathrm{~min}$, followed by washing 2-3 times with $200 \mu \mathrm{L}$ of PBS. Diluted antibodies (antiCD3, anti-CD4, anti-CD8, anti-CD25, anti-CD19, antiCD11b, anti-CD27 and anti-Foxp3 antibodies) were added to their respective wells, incubated at $4^{\circ} \mathrm{C}$ under gentle shaking for $60 \mathrm{~min}$, and washed 2-3 times with $200 \mu \mathrm{L}$ of PBS. Then, cells were resuspended in $200 \mu \mathrm{L}$ of cold PBS and kept in the dark for determination of the total numbers of CD3+ T cells, Th cells of the $\mathrm{CD}^{+}$ $\mathrm{CD} 4^{+}$phenotype, CTL cells of the $\mathrm{CD}^{+} \mathrm{CD}^{+}$phenotype, $\mathrm{B}$ cells of the $\mathrm{CD}^{-} \mathrm{CD} 19^{+}$phenotype, NK cells of the $\mathrm{CD} 11 \mathrm{~b}^{+} \mathrm{CD} 27^{+}$phenotype, and Treg cells expressing $\mathrm{CD} 4^{+} \mathrm{CD} 25^{+}$Foxp $^{+}$by flow cytometry (BD Biosciences, Franklin Lake, NJ, USA).

\section{MTT detection of CTL and NK activity}

Using the random number method, three mice models were detected by MTT in each group. Spleen cells (NK and CTL cells) were enumerated by flow cytometry. Their densities were then adjusted to $1 \times 10^{6} / \mathrm{mL}$. YAC- 1 and $\mathrm{H} 22$ were used as target cells for NK and CTL reactivity, respectively. Cells were incubated in RPMI 1640 containing $10 \%$ fetal bovine serum at $37^{\circ} \mathrm{C}$ in an atmosphere of $5 \% \mathrm{CO}_{2}$ in air for $48 \mathrm{~h}$. Cell density was adjusted to $1 \times 10^{5} / \mathrm{mL}$. Three mice were randomly selected in each group for detection of CTL and NK cell activity. One hundred $\mu \mathrm{L}$ of spleen and target cells (at an effector:target cell ratio of 10:1) were added to a 96well staining plate. After $18 \mathrm{~h}$ of incubation, MTT $(20 \mu \mathrm{L})$ was added to each well and incubated for an additional $4 \mathrm{~h}$. After centrifugation, the supernatant was removed, and dimethyl sulfoxide (DMSO) $(200 \mu \mathrm{L})$ was added and agitated for $20 \mathrm{~min}$. Absorbance was determined at a wavelength of $570 \mathrm{~nm}\left(\mathrm{~A}_{570}\right)$. The activity of CTL and NK cells were calculated as follows:

Activity $=\left(1-\left(\mathrm{A}_{570}\right.\right.$ of effector-target cells $-\mathrm{A}_{570}$ of effector cells $)$ $/ \mathrm{A}_{570}$ of target cells) $\times 100 \%$ 


\section{Observation of NK cells and CTL by fluorescence microscopy}

NK cells and CTL were detected by flow cytometry according to the method described above. NK cells or CTL were permitted to attach to the coverslips in 6-well plates, following which, the medium was removed, the plates were rinsed twice with PBS, and $2 \mathrm{~mL} 4 \%$ paraformaldehyde was added to each well. Plates were incubated at room temperature for $20 \mathrm{~min}$, rinsed with $2 \mathrm{~mL}$ PBS three times for 5 min every time. Cells were permeabilized with $2 \mathrm{~mL} 0.1 \%$ Triton X-100 in phosphate buffered saline solution at $4^{\circ} \mathrm{C}$ for $10 \mathrm{~min}$, aspirated, and cells were rinsed in PBS for $5 \mathrm{~min}$ at room temperature. Next, non-specific interactions were blocked with $4 \%$ bovine serum albumin in phosphate buffered saline solution at $37^{\circ} \mathrm{C}$ for $30 \mathrm{~min}$, and primary antibody solution was added and incubated at $4^{\circ} \mathrm{C}$ overnight. The primary antibody solution was removed, washed in PBS for 5 min, add secondary antibody solution was added to the cells and incubated at room temperature for $1 \mathrm{hr}$. Cells were washed in PBS three times for 5 min each, following which anti-fade DAPI solution was added if needed. Finally NK cells or CTL were observed by fluorescence microscopy.

\section{Data analysis}

All data were expressed as mean \pm standard deviation (SD). One-way analysis of variance (ANOVA) and the least significance difference (LSD) test were used for inter-group comparisons of the data. Kaplan-Meier survival plots were used for calculation of survival data. For all analyses, a probability less than an alpha value of 0.05 $(P<0.05)$ were considered significantly different among groups.

\section{Results}

Identification of the new vector PGM-CSF-GFP-IRES-Rae-1IL-21

According to the pIRES vector map (Figure 1A-B), the genes of GFP, IL-21, GM-CSF and Rae-1 were built into the empty plasmid and the new vector pGM-CSF-GFPIRES-Rae-1-IL-21 was constructed. The positive clones were selected by restriction endonuclease, and the precise clones were confirmed by DNA sequence analyses and end-use sequences. The band of the GFP product (720 bp) was obtained by cutting pGM-CSF-GFP-IRESRae-1-IL-21 by EcoRI and MluI, and had the same size as the target gene. Likewise, the band of the GM-CSF product (425 bp) was obtained by cutting pGM-CSF-GFPIRES-Rae-1-IL-21 by XhoI and EcoRI, and had the same size as the target gene. The band of Rae-1 (1106 bp) that was obtained by cutting pGM-CSF-GFP-IRES-Rae-1-IL21 with Xba1 and Sal1 had the same size as the target gene. The band of the IL-21 (441 bp) product was obtained by cutting pGM-CSF- GFP-IRES-Rae-1-IL-21 by Sal1and Not1, and had the same size as the IL-21 target gene. The obtained genes of GFP, GM-CSF, Rae-1, and IL-21 were identical with the original sequences as defined

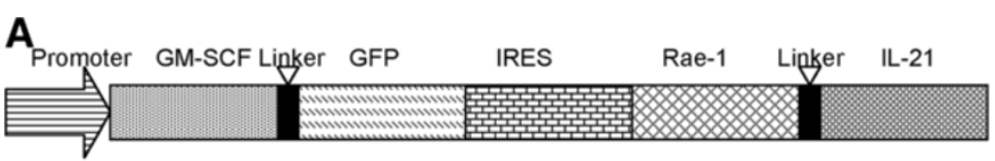

B

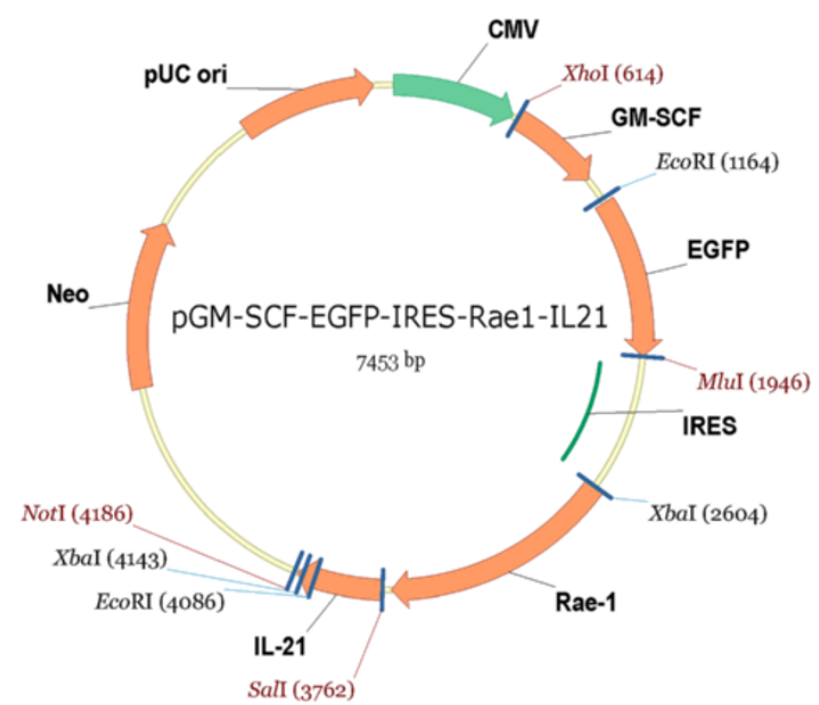

Figure 1 Design and construction of the new expression vector PGM-CSF-GFP- IRES-Rae-1-IL-21. A: Design and construction of the immune escape inhibitory system; $\mathbf{B}$ : the map of the pIRES expression vector. 
in Genbank, and confirmed that the new vector was successfully constructed (DNA sequence analysis data not shown).

\section{Inhibitory effect of pGM-CSF-GFP-IRES-Rae-1-IL-21 on mouse liver cancer}

After 10 days of treatment, mice in each group were sacrificed by overdosing of anesthesia and mice were then routinely dissected for their livers cancer specimens. The histological analyses were performed on the tumor sites, and revealed that the IRES/combination group were infiltrated by massive numbers of monocytes and neutrophils, the tumors had obviously shrunk, experienced ordered rarefaction, and had degenerated (Figure $2 \mathrm{~A}(\mathrm{f})$ ). In the IRES/GM- SCF-IL-21 group, infiltration of immunocytes had increased appreciably and necrotic tumor cells were noticeable in the tumor tissue (Figure $2 \mathrm{~A}(\mathrm{e})$ ). In the IRES/GM-SCF or IRES/IL-21 group the tumor cells grew slowly, and there were few immunocytes infiltrating the tumor tissues (Figure $2 \mathrm{~A}(\mathrm{c}-\mathrm{d})$ ). By contrast, the active growth of the tumor cells, and obvious nuclear division or diverse nucleic type, was found in both the control and the IRES/GFP groups (Figure 2A(a-b)).

Histological analyses suggested that the GM-SCF, IL-21, and Rae-1 genes alone or in combination induced a cellular immune response against $\mathrm{H} 22$ tumor cells. The specimens were weighed and the results described (Figure 2B). The tumor weight averaged $0.207,0.522,0.873,0.843$, 1.439, and $1.591 \mathrm{~g}$ for IRES/combination, IRES/GM-SCFIL-21, IRES/GM-SCF, IRES/IL-21, IRES/GFP, and the control group, respectively, which were significantly different $(\mathrm{P}<0.01)$. The tumor was also significantly $(\mathrm{P}<0.01)$ lighter in the IRES/GM-SCF-IL-21 group than was found in either the IRES/GM-SCF or IRES/IL-21 groups and was not significantly different $(\mathrm{P}>0.05)$ between either the IRES/GM-SCF group or the IRES/IL-21 group.

The tumor was significantly heavier in the control group and lightest in the IRES/combination among the six groups $(\mathrm{P}<0.05)$. By $1-5$ days after treatment, the tumor volume had gradually increased in all groups (Figure $2 \mathrm{C}$ ). After 6 days, the tumor volume had gradually decreased in the IRES/combination group, and was marginally suppressed in the IRES/GM-SCF-IL-21, IRES/GM-SCF, and IRES/IL-21 groups, but had increased rapidly in both the IRES/GFP and control groups. At the conclusion of treatments, tumors were significantly smaller $(\mathrm{P}<0.01)$ in the IRES/GM-SCF-IL-21 group than was found in either the IRES/GM-SCF or IRES/IL-21 groups but this was not significantly different $(\mathrm{P}>0.05)$. The tumor volume of the mice was highest in both the IRES/GFP group and the control group $(\mathrm{P}<0.01)$ and smallest in the IRES/combination group $(\mathrm{P}<0.01)$.

The mice models of subcutaneous liver cancer were randomly divided into six groups with 13 mice in each group and were treated with the procedure described above to record their survival rates by the Kaplan-Meier survival method. Mouse survival was found to decline, with the first deaths seen at $6,5,17,15$, and 21 days after treatment in the control, IRES/GFP, IRES/GM-SCF, IRES/IL-21, and IRES/GM-SCF-IL-21 groups respectively (Figure 2D). All mice had demised by 14 and 16 days after treatment in the control and IRES/GFP groups, respectively. There were 2,1 , and 11 mice surviving 60 days after treatment in the IRES/GM-SCF, IRES/IL-21, and IRES/GM-SCF-IL-21 groups respectively. The survival rates of mice were $73.33 \%, 13.33 \%$, and $6.67 \%$ at 60 days of treatment for groups IRES/GM-SCFIL-21, IRES/GM-SCF and IRES/IL-21, respectively. The survival rate of the mice was significantly higher in the IRES/GM-SCF-IL-21 than was found in the other groups.

\section{Effect of pGM-CSF-GFP-IRES-Rae-1-IL-21 on IL-2 and INF- $\gamma$ levels}

The levels of IL-2 and INF- $\gamma$ of mice 1-6 days after treatment gradually increased in the IRES/combination groups, including IRES/GM-SCF-IL-21, IRES/GM-SCF and IRES/IL-21 (Figure 3A-B). They were highest in the IRES/combination group and lowest $(\mathrm{P}<0.01)$ in the IRES/GM-SCF and IRES/IL-21 groups, with the IRES/ GM-SCF-IL-21 group showing intermediate levels. By 6-10 days after treatment, IL-2 and INF- $\gamma$ levels had stably increased in the IRES/combination groups, but had gradually decreased in the IRES/GM-SCF-IL-21, IRES/GM-SCF and IRES/IL-21 groups. At the end of treatment, IL-2 and INF- $\gamma$ levels were significantly higher in the IRES/GMSCF-IL-21 group than were found in either the IRES/GMSCF group or IRES/IL-21 group $(\mathrm{P}<0.01)$, which were also significantly higher than either the IRES/GFP or control groups $(\mathrm{P}<0.01)$. The levels of IL-2 and INF- $\gamma$ were highest in the IRES/combination group $(\mathrm{P}<0.01)$ and not significantly $(\mathrm{P}>0.05)$ different among the IRES/GM-SCF, IRES/IL-21, IRES/GFP, and control groups. By 1-10 days after treatment, IL-2 and INF- $\gamma$ levels remained unaltered in the IRES/GFP and control groups.

\section{Effect of pGM-CSF-GFP-IRES-Rae-1-IL-21 on expression of Rae-1 and protein in liver cancer tissue}

RT-PCR and Western blot assays were used to detect liver cancer tissues and to analyze the effect of GFP, GM-SCF, IL-21 and Rae-1 constructs and protein expression in liver cancer tissue. The genes and protein expressions of GM-SCF in IRES/GM-SCF, IRES/GM-SCF- IL21 and the IRES/combination group were significantly enhanced (Figure 3C-D). Similarly, the expression of IL-21 in IRES/IL21, IRES/GM-SCF-IL21 and IRES/combination groups were significantly increased (Figure 3C-D). Moreover, Rae-1 mRNA and protein expression in the IRES/ combination group was the highest, and the gene and 


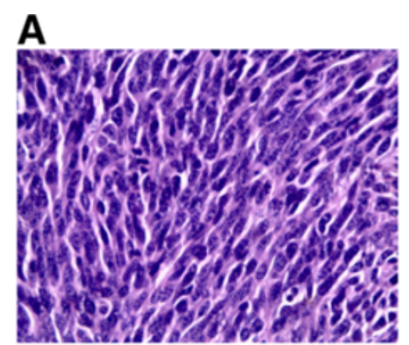

(a) control group (HE $\times 400)$

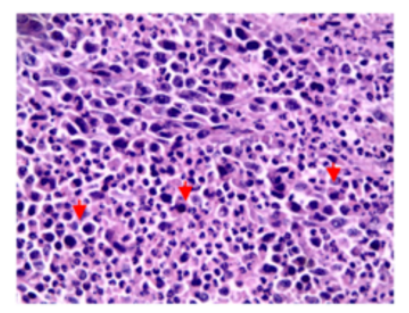

(d)IRES/GM-SCF group (HE $\times 400)$

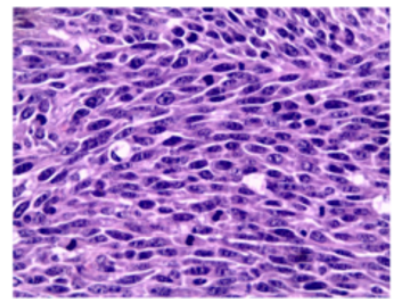

(b) IRES/GFP group $(\mathrm{HE} \times 400)$

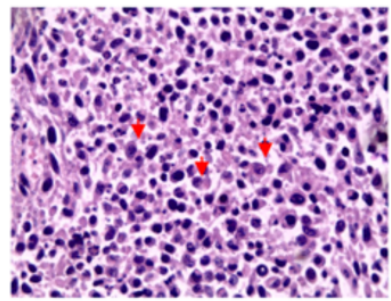

(e) IRES/GM-SCF-IL-21 (HE $\times 400)$

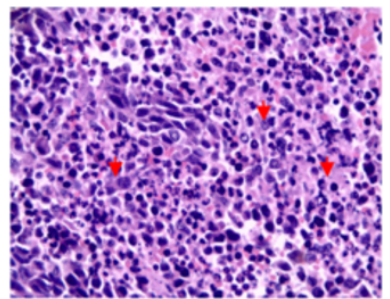

(c) IRES/IL-21 group (HE $\times 400)$

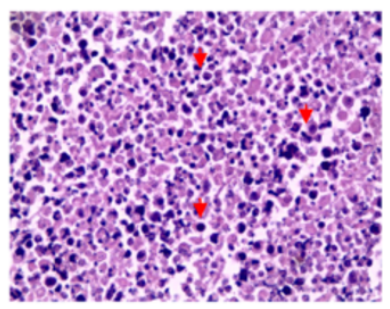

(f) IRES/combination (HE $\times 400)$

B

C
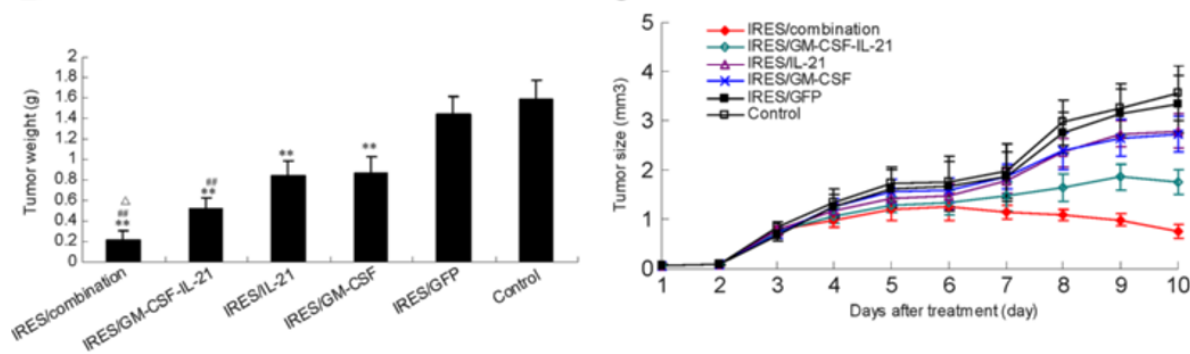

D

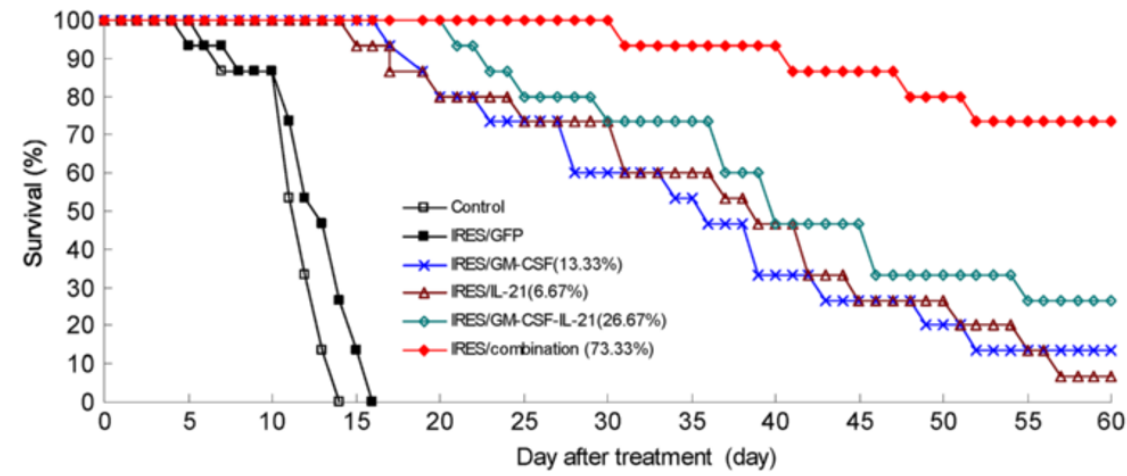

Figure 2 Inhibitory effects of different expression plasmids on liver cancer in a mouse model. The differential plasmid treatments were: Control, pGFP-IRES, pGM-CSF-IRES, pIL-21-IRES, pGM-CSF-IRES-IL-21, and pGM-CSF-GFP-IRES-Rae-1-IL-21. Tumor-bearing mice were sacrificed $10 \mathrm{~d}$ after treatment and histological sections were made from various tumor tissues. A; Histopathology of tumor tissues in mouse liver cancer (HE $\times 400$ magnification). (a) and (b) shows histopathological tumor tissue sections in mice treated with PBS or pGFP-IRES, wherein the tumor cells grew actively. (c) and (d) shows histopathological sections from the tumor tissue of tumor-bearing mice treated with pGM-CSF-IRES or plL-21-IRES, wherein the tumor cells grew slowly, and only few immunocytes were seen infiltrating the tumor tissue. (e) showing histopathological sections from the tumor tissues of tumor-bearing mice treated with pGM-CSF-IRES-IL-21. Infiltration of immunocytes increased appreciably and necrotic tumor cells were noticeable in the tumor tissue. ( $f$ ) showing histopathological sections of the tumor tissues in tumor-bearing mice treated with pGM-CSF-GFP-IRES-Rae-1-IL-21. Here, both monocytes and neutrophils infiltrated the tumor, and there was evidence of mass necrosis seen in the tumor tissue. Note that the red arrow indicates inflammatory cells. B; showing the tumor weights (expressed as mean \pm standard deviation) of mice in each group $10 \mathrm{~d}$ after treatment $(n=10)$. C ; tumor volumes of mice (expressed as mean \pm standard deviation) in each group 1-10 d after treatment $(n=10)$. D; showing the survival time of the mice in each group $(n=13)$ that were analyzed by the Kaplan-Meier approach. Note: ${ }^{* *} \mathrm{P}<0.01$, as compared with the control. ${ }^{\# \#} \mathrm{P}<0.01$, as compared with the IRES/GM-SCF or IRES/IL21 expression constructs. ${ }^{.} \mathrm{P}<0.05$, as compared with the IRES/GM-SCF-IL-21 expression construct. 


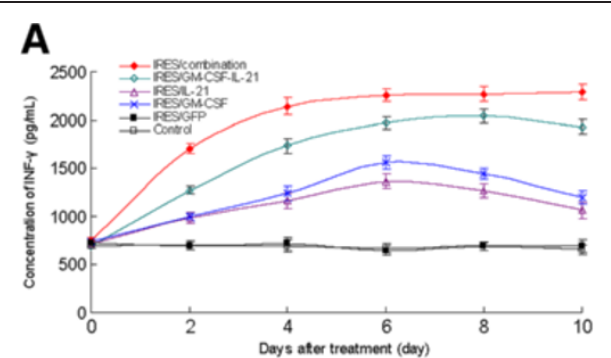

B
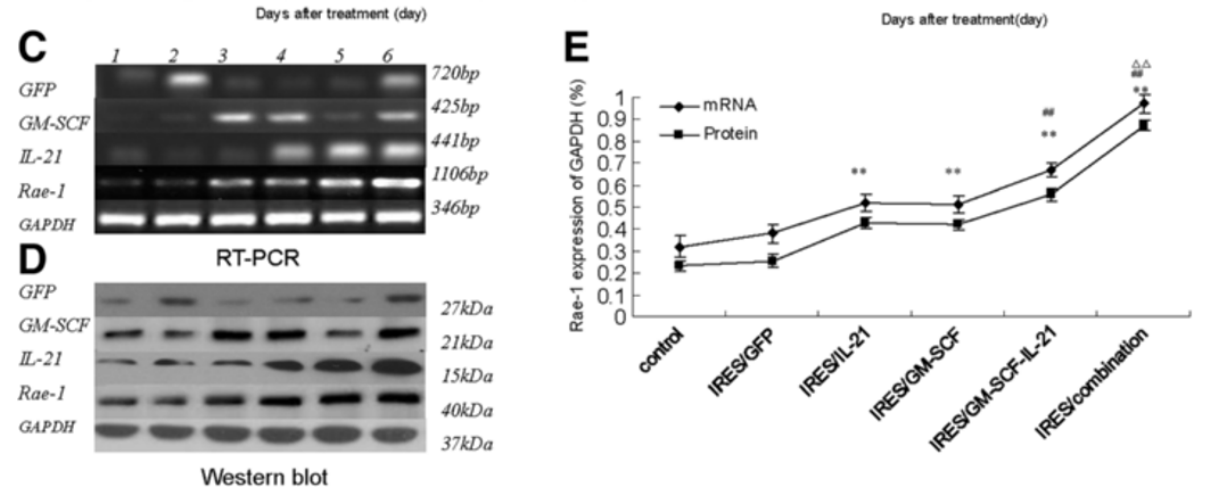

Figure 3 IL-2 and INF- $\gamma$ levels in mouse serum and expression of GPF, GM-SCF, IL-21 and Rae-1 in liver cancer tissue in each treatment group. Effect of the plasmids on IL-2 and INF- $\gamma$ levels in mouse serum of each group that included: control, pGFP-IRES, pGM-CSF-IRES, pIL21-IRES, pGM-CSF-IRES-IL21, and pGM-CSF-GFP-IRES-Rae-1-IL-21. At 10d after treatment, mouse serum was quantified by ELISA for IL-2 levels and INF- $\gamma$ levels. Tumor tissue was assessed by RT-PCR and Western blot to determine GPF, GM-SCF, IL-21 and Rae-1 expression. A: IL-2 levels were detected and expressed as mean \pm standard deviation $(n=3)$; B: INF- $\gamma$ levels were tested by ELISA and expressed as mean \pm standard deviation $(n=3)$; C: RT-PCR analysis of GPF, GM-SCF, IL-21 and Rae-1 in liver cancer tissue $(n=3)$. D: Western blot analysis of GPF, GM-SCF, IL-21 and Rae-1 in liver cancer tissue $(n=3)$. D: Western blot analysis of GPF, GM-SCF, IL-21 and Rae-1 in liver cancer tissue $(n=3)$. E: relative values of Rae-1 protein or mRNA expression in liver cancer tissue of each group, expressed as mean \pm standard deviation $(n=3)$. Note: Lane 1, control. Lane 2, pIRES/GFP. Lane 3, pIRES/IL2. Lane 4, pIRES/GM-SCF. Lane 5, pIRES/GM-SCF-IL21. Lane 6, pIRES/combination. ${ }^{*} \mathrm{P}<0.05$ and ${ }^{* *} \mathrm{P}<0.01$, as compared with control. ${ }^{\#} \mathrm{P}<0.05$ and ${ }^{\# \#} \mathrm{P}<0.01$, as compared with IRES/GM-SCF and IRES/IL21. ${ }^{\Delta} \mathrm{P}<0.05$ and ${ }^{\Delta \Delta} \mathrm{P}<0.01$, as compared with IRES/GM-SCF-IL21.

protein expression of GFP were markedly higher in the IRES/GFP and IRES/combination group. These observations informed us that the recombinant plasmids were successful constructed and transfected in vivo and were stably expressed. Expression of Rae-1 and protein were significantly $(\mathrm{P}<0.01)$ different among the six groups (Figure 3C-E). Rae-1 was also significantly $(\mathrm{P}<0.01)$ higher in the IRES/combination group as compared with the IRES/GM-SCF-IL-21, IRES/IL-21, or IRES/ GM-SCF groups, and was significantly $(\mathrm{P}<0.01)$ higher in the IRES/GM-SCF-IL-21 group as compared with the IRES/IL-21 or IRES/GM-SCF groups. Rae-1 expression was also significantly $(\mathrm{P}<0.01)$ higher in the IRES/IL-21 or IRES/GM-SCF groups than in the IRES/GFP and control groups. However, expression of Rae-1 was not significantly $(\mathrm{P}>0.05)$ different between the IRES/IL-21 and IRES/GM-SCF groups, or when compared with either the IRES/GFP and control groups.

Effect of pGM-CSF-GFP-IRES-Rae-1-IL-21 on the frequencies of NK and CTL cells, cellular cytotoxicity and Treg ratios in mouse spleen

In order to study the putative mechanisms responsible for the inhibitory effects of the pGM-CSF-GFP-IRES-
Rae-1-IL-21 construct on liver cancer tumors, we measured spleen cell frequencies by flow cytometry and MTT assays. We determined that the proportion of CD3-CD19+, $\mathrm{CD} 3+\mathrm{CD} 4+$ and CD3+ cells in mouse spleen were not significantly $(\mathrm{P}>0.05)$ different before or after treatment (Figure 4D). The proportion and cytotoxicities of both NK and CTL cells were significantly $(\mathrm{P}<0.01)$ different among the six groups (see Figure 4A-B, and Table 2). When compared with the control group, the frequency and cytotoxicity of NK and CTL cells were significantly $(\mathrm{P}<0.01)$ increased in the IRES/combination, IRES/GM-SCF-IL-21, IRES/IL-21, and IRES/GM-SCF groups, especially in respect of the IRES/combination. The proportion and cytotoxicity of NK and CTL cells were significantly $(\mathrm{P}<0.01)$ higher in the IRES/GM-SCF or IRES/GM-SCF-IL-21 groups than in the IRES/IL-21 group. There was no significant $(P>0.05)$ difference between either the control or the IRES/GFP group, or between the IRES/IL-21 and IRES/GM-SCF groups. The CTL and NK cells showed green fluorescence in the IRES/combination and IRES/ GFP group (Figure 5), and the fluorescence intensity of both CTL and NK cells in the IRES/combination group was significantly stronger as compared with the IRES/GFP group. In addition, there was no green fluorescence in 


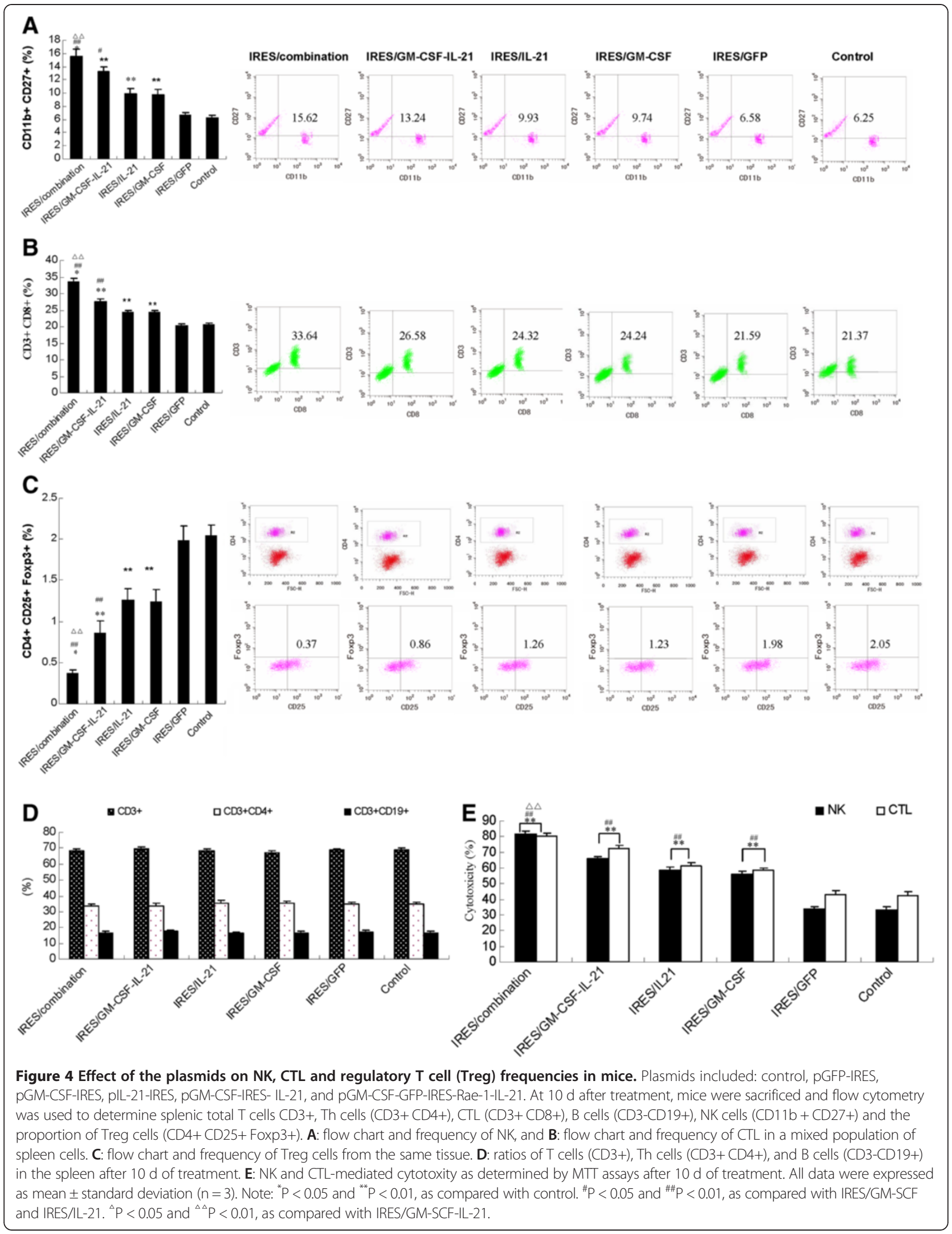


Table 2 The raw data showing the frequency of NK, CTL and Treg cells in each group $(\mathbf{n}=\mathbf{3})$

\begin{tabular}{|c|c|c|c|c|c|c|}
\hline \multirow{3}{*}{$\begin{array}{l}\text { Group } \\
\text { IRES/combination group }\end{array}$} & \multirow{2}{*}{\multicolumn{2}{|c|}{$\begin{array}{c}\mathrm{CD} 11 \mathrm{~b}+\mathrm{CD} 27+(\%) \\
\mathrm{NK}\end{array}$}} & \multirow{2}{*}{\multicolumn{2}{|c|}{$\begin{array}{c}\mathrm{CD} 3+\mathrm{CD} 8+(\%) \\
\mathrm{CTL}\end{array}$}} & \multirow{2}{*}{\multicolumn{2}{|c|}{$\begin{array}{c}\text { CD4 + CD25 + Foxp3 + (\%) } \\
\text { Treg cells }\end{array}$}} \\
\hline & & & & & & \\
\hline & 16.24 & & 34.58 & & 0.41 & \\
\hline & 15.62 & $15.60 \pm 0.66$ & 33.64 & $33.60 \pm 1.00$ & 0.37 & $0.37 \pm 0.04$ \\
\hline & 14.95 & & 32.59 & & 0.33 & \\
\hline \multirow[t]{3}{*}{ IRES/GM-CSF-IL21 group } & 13.78 & & 27.93 & & 1.01 & \\
\hline & 13.24 & $13.40 \pm 0.33$ & 26.58 & $26.59 \pm 1.33$ & 0.86 & $0.87 \pm 0.14$ \\
\hline & 13.18 & & 25.27 & & 0.73 & \\
\hline \multirow[t]{3}{*}{ IRES/IL21 group } & 10.32 & & 24.78 & & 1.34 & \\
\hline & 9.93 & $10.03 \pm 0.26$ & 24.32 & $24.36 \pm 0.41$ & 1.26 & $1.26 \pm 0.07$ \\
\hline & 9.83 & & 23.97 & & 1.19 & \\
\hline \multirow[t]{3}{*}{ IRES/GM-CSF group } & 9.97 & & 24.79 & & 1.32 & \\
\hline & 9.74 & $9.80 \pm 0.15$ & 24.24 & $24.07 \pm 0.82$ & 1.23 & $1.21 \pm 0.12$ \\
\hline & 9.69 & & 23.18 & & 1.09 & \\
\hline \multirow[t]{3}{*}{ IRES/GFP group } & 6.72 & & 21.97 & & 2.01 & \\
\hline & 6.58 & $6.60 \pm 0.11$ & 21.59 & $21.61 \pm 0.36$ & 1.98 & $1.95 \pm 0.08$ \\
\hline & 6.51 & & 21.26 & & 1.86 & \\
\hline \multirow[t]{3}{*}{ Control group } & 6.45 & & 21.73 & & 2.20 & \\
\hline & 6.25 & $6.36 \pm 0.10$ & 21.37 & $21.46 \pm 0.24$ & 2.05 & $2.08 \pm 0.11$ \\
\hline & 6.37 & & 21.28 & & 1.98 & \\
\hline
\end{tabular}

other groups because they lacked the GFP gene. These observations further confirmed the effect of NK and CTL cells against targeted tumor cells.

At the end of treatment, the frequencies of Tregs were significantly different among groups (Figure $4 \mathrm{C}$ and Table 2). When compared with control, Tregs were significantly $(\mathrm{P}<0.01)$ fewer in number in the IRES/combination groups, IRES/ GM-SCF-IL-21, IRES/IL-21 and IRES/GMSCF groups. Tregs were also significantly $(\mathrm{P}<0.01)$ lower in the IRES/GM-SCF- IL-21 group than in either the IRES/IL-21 or the IRES/GM-SCF groups. No significant ( $P>0.05)$ difference was found between either the IRES/ IL-21 group or the IRES/GM-SCF group, or between the control and IRES/GFP groups. These observations indicated that pGM-CSF-GFP-IRES-Rae-1-IL-21 significantly inhibited the growth of liver tumors by lowering the Treg frequency, increasing immune modulation, frequency and cytotoxic activities of immune cells like CTL and NK cells, enhancing Rae-1 expression in liver cancer tissues, and facilitating the recognition of tumor cells by CTL and NK cells and debulking liver cancer.

\section{Discussion}

The development of tumors is related to the relative competence of host immunity [16]. As with other tumors, liver cancer induces a relative state of immune suppression or dampening of host immunity, and a change in the molecular expression of surface markers by cancer cells that permits the escape of tumor cells from immune recognition [17] by such cells as NK and CTL cells. Meanwhile, in tumor cells that are recognized by CTL and NK cells (e.g., MHC-1 ligand and Rae-1) obviously decrease or disappear, and liver cancer cells survive in the host $[18,19]$. Current studies on the treatment of tumors by GM-SCF or IL-21 mostly focus on enhancing CTL and NK cell-mediated activity $[20,21]$ or increasing genes that can be expressed by tumors and recognized by NK and CTL cells in tumor tissues [22]. Such strategies rarely endeavor to simultaneously increase cell-mediated activity or genes that are recognized by NK and CTL cells in tumors.

In this study, we successfully constructed an immune escape inhibition system (Figure 1A), which was afforded by the construction of the recombinant expression plasmid pGM-CSF-GFP-IRES- Rae-1-IL-21 that passed RT-PCR and gene sequencing analyses to augment host immunity and proteins that are expressed by tumor cells and then recognized by host immune cells. The recombinant plasmid (IRES/combination) used in this mouse model of subcutaneous liver cancer resulted in decreased tumor weights as compared mice that were transfected with IRES/GM-SCFIL-21, IRES/GM-SCF and IRES/IL-21 treatment alone. In the IRES/combination transfected animals, the tumor volume was the least by the end of treatment. By 1-5 d after treatment, the tumor volume in each group gradually increased, which might be related to a weak inhibition of 


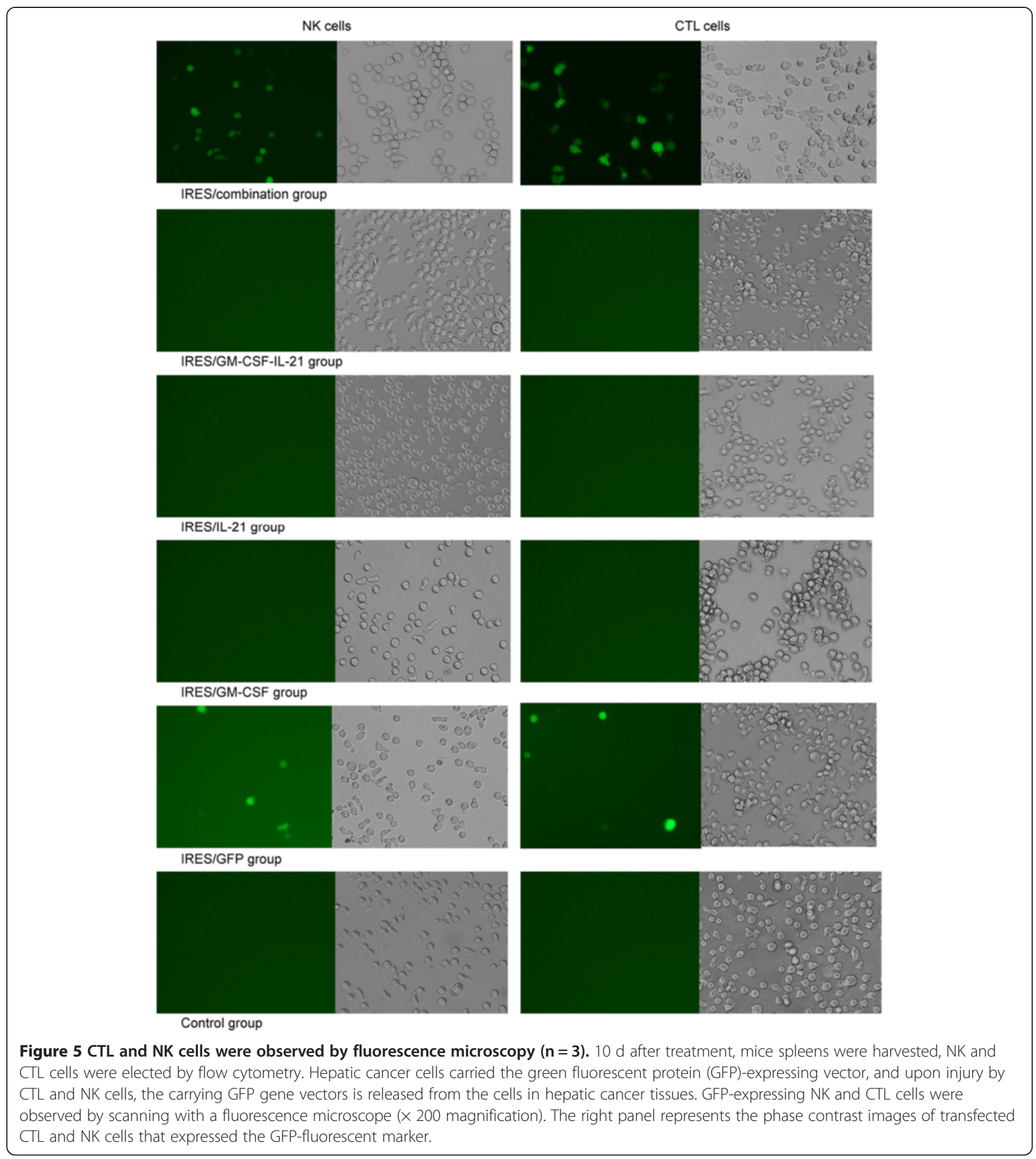

the tumor caused by low gene expression at the beginning of treatment. By 6-10 d after treatment, the tumor volume in the IRES/combination group was decreased, which might be associated with a potent anti-tumor effect caused by high expression of the target genes. In the other groups, the tumor volume increased at a much lower rate or even decreased. This observation indicated an inhibitory effect of these genes on tumor size. Among the groups, the anti-tumor inhibitory effect of the IRES/combination was highest and tumor cell necrosis, monocyte- and neotrophilic-infiltration were more obvious in the tumor tissues (Figure $2 \mathrm{~A}(\mathrm{f})$ ). We also found that the survival rates of mice were highest in the IRES/combination group, which indicated that recombinant genes of GM-SCF, IL-21, and Rae-1 displayed the most effective treatment against liver cancer. 
Cytokines belong to small active molecules produced by immune cells. Cytokines have potent immune-regulating effects, and play important roles in tumor immunity $[23,24]$. GM-SCF and IL-21 augment expression of INF- $\gamma$ and IL-2, improve the activity of CTL and NK cells, and inhibit growth of tumors $[25,26]$. Our study showed that levels of both INF- $\gamma$ and IL-2 in mice treated with recombinant GM-CSF, IL-21 and Rae-1 gene expression vectors were highly expressed and negatively associated with the tumor volumes seen in tumor-bearing mice. The numbers and activity of CTL an NK cells in the IRES/combination groups were higher than was seen in the IRES/GM-SCFIL-21, IRES/GM-SCF, and IRES/IL-21 groups, indicating that the GM-SCF, IL-21 and Rae-1 genes had a synergistic effect in promoting secretion of INF- $\gamma$ and IL-2 levels, and the numbers and activity of CTL and NK cells. INF- $\gamma$ is secreted by CTL and NK cells and belongs to the glycoprotein family. INF- $\gamma$ displays potent anti-viral effects, and is involved in immune regulation, has anti-proliferative effects, displays other biological characteristics $[27,28]$ and directly inhibits tumor cells. INF- $\gamma$ displays immunoregulatory effects and activates enhanced phagocytic functions of both mononuclear macrophages and NK cells. INF- $\gamma$ also enhances the differentiation and maturation of $\mathrm{B}$ and T cells, increases the cytotoxic activity of CTL cells, induces the expression of MHC-I antigens by tumor cells, and increases the recognition of tumors by immune cells such as CTL and NK cells [29].

The cytokine IL-2 is a growth factor of T cells, and is important in the activation and proliferation of $\mathrm{T}$ cells, activates $\mathrm{B}$ cells and macrophages, and activates $\mathrm{T}$ cells to secrete IL-2 [30]. Therefore, in this study, the combination of GM-SCF, IL-21 and Rae-1 collectively activated the murine immune system in liver cancer, and increased the numbers and cytotoxic activities of NK and CTL cells. Activated CTL and NK cells secreted INF- $\gamma$, and high INF- $\gamma$ levels enhanced the numbers and cytotoxic activities of NK and CTL cells. Likewise, the release of IL-2 promoted significant activation of CTL in an autocatalytic immunological cycle that finally inhibited tumor growth.

We found that the expression of Rae-1 and protein was significantly higher in the IRES/combination group as compared with the other groups, and that GM-SCF and IL-21 stimulated the expression of the Rae-1 gene. Most NK and CTL cells express the Rae-1 receptor, which easily combines with Rae-1 that is expressed by liver cancer tissues to enhance the removal of cancer tissue by NK cells and CTL [31]. Our study showed that pGM-CSF-IL-21-Rae-1 increased the number and cytotoxicity of CTL and NK cells, and enhanced the expression of Rae-1 in liver cancer tissues. Therefore, CTL and NK cells that expressed the Rae-1 receptor efficiently eliminated Rae-1.
Tregs belong to a subgroup of $\mathrm{T}$ cells that are of special immune regulatory importance, and are important in tumor immunity. Foxp3 is a special transcription factor expressed by Tregs and it is essential for their development and function [32]. First, as with other tumors, liver cancer causes an increase in the frequency of Tregs and immune inhibition by non-specific suppression of major histocompatibility complex (MHC), and second it causes specific suppression. In the first mechanism, there is broad inhibition of immunity including effects on dentritic cells, NK cells, macrophages, and CD4+ and CD8+ T cell sub-populations [33,34]. In specific suppression, Treg is of special $\mathrm{T}$ cell receptor immune complex (TCR) importance and displays specific MHC restriction. Thus, antigens related to specific tumors activate Tregs. Active Tregs inhibit activation of CD4+, CD8+ T cells and $\mathrm{B}$ cells, which can finally result in the resistance of immune cells to tumor antigens [35]. In this study, we treated liver cancer with a recombinant plasmid of GMSCF, IL-21 and Rae-1 and found that the frequency of Tregs was significantly decreased as compared with treatment using a single gene. This observation indicated that the recombinant plasmid played a synergistic effect on the decrease in Treg frequencies. It was previously reported that IL-21 enhances activation and cytotoxicity of CTL and NK cells, and alleviates immune inhibition of Tregs [36,37]. As an anti-apoptotic cytokine, IL-21 can sustain survival of active T cells [36,37]. Tian Yongju [38] found that IL-21 decreases Treg frequencies and apoptosis of peripheral blood mononuclear cells (PBMC), and greatly increases the cytotoxicity of PBMC, which can be alleviated by IL-21 antibodies. However, thus far, little information has detailed the effects of GM-SCF and Rae- 1 gene expression on Treg frequencies in a mouse tumor model. Here, we have attempted to confirm that IL-21 decreased the frequency of Tregs. Further, this effect was promoted by expression of GM-SCF and Rae-1. The mechanisms involved in this effect require further study.

\section{Conclusion}

In summary, GM-SCF, IL-21 and Rae- 1 greatly inhibited the growth of liver cancer in a relevant mouse model. The mechanisms responsible for this inhibitory effect might be related to the activation of host cell-mediated immunity that was induced by the triple gene expression vector. We also propose that this might have increased the numbers and cytotoxicity of NK and CTL cells, lowered Treg frequency, and alleviated any inhibition of CTL and NK cells. Active CTL and NK cells increased their ability to secrete INF- $\gamma$ that augments activation and cytotoxicity of NK and CTL cells. Similarly, active CTLs increased their ability to secrete IL-2 that can drive activation and cytotoxicity of CTL. In an autocatalytic cascade of cell-mediated immunity and immune 
pathways, the recombinant triple-gene expression plasmid increased Rae-1 expression in cancer, thus efficiently eliminating this tumor by the combined activities of CTL and NK cells that express cell membrane-associated Rae-1 receptors.

\section{Competing interests}

The authors declare that they have no competing interests.

\section{Authors' contributions}

$\mathrm{MC}$ and $\mathrm{BH}$ participated in the study design, performing experiments, data analysis and drafting of the manuscript. $K Z$ and $X G$ performed in vitro experiments and data analysis. $\mathrm{YL}$ and $\mathrm{JH}$ participated in the study design and manuscript editing. ZZ and YW were involved in the conception and design of the study, data preparation and analysis, manuscript drafting and revisions. All authors read and approved the final draft of the manuscript.

\section{Acknowledgements}

This work was supported by the Natural Science Foundation of Shanghai (12 nm0502202 and 114119a4700), the Pudong New Area Science and Technology Development Fund (PKJ2012-Y24), and the Pudong New Area Health System discipline lead development program (PWRd2013-10).

\section{Author details}

'Department of General Surgery, Pudong New Area District Zhoupu Hospital, Shanghai 201318, China. ²Department of Endoscopy, Pudong New Area District Zhoupu Hospital, Shanghai 201318, China. ${ }^{3}$ Department of Vascular \& Endovascular Surgery, Changzheng Hospital, the Second Military Medical University, Shanghai 200003, China. ${ }^{4}$ Department of Plastic Surgery, Pudong New Area District Zhoupu Hospital, Shanghai 201318, China. ${ }^{5}$ Department of General Surgery, Shanghai Fifth People's Hospital, Fudan University, Shanghai 200240, China

Received: 2 August 2013 Accepted: 7 December 2013 Published: 18 December 2013

\section{References}

1. BURNET M: Auto-immune disease. I. Modern immunological concepts. Br Med J 1959, 2:645-650.

2. Li Q, Rao RR, Araki K, Pollizzi K, Odunsi K, Powell JD, Shrikant PA: A central role for mTOR kinase in homeostatic proliferation induced CD8+ T cell memory and tumor immunity. Immunity 2011, 34:541-553.

3. Zhang S, Bernard D, Khan WI, Kaplan MH, Bramson JL, Wan Y: CD4+ T-cell-mediated anti-tumor immunity can be uncoupled from autoimmunity via the STAT4/STAT6 signaling axis. Eur I Immunol 2009, 39:1252-1259

4. Mehling M, Simon P, Mittelbronn M, Meyermann R, Ferrone S, Weller M, Wiendl $\mathrm{H}$ : WHO grade associated downregulation of MHC class I antigen-processing machinery components in human astrocytomas: does it reflect a potential immune escape mechanism? Acta Neuropathol 2007, 114:111-119.

5. Yokomaku Y, Miura H, Tomiyama H, Kawana-Tachikawa A, Takiguchi M, Kojima A, Nagai Y, Iwamoto A, Matsuda Z, Ariyoshi K: Impaired processing and presentation of cytotoxic-T-lymphocyte (CTL) epitopes are major escape mechanisms from CTL immune pressure in human immunodeficiency virus type 1 infection. J Virol 2004, 78:1324-1332.

6. Farnault L, Sanchez C, Baier C, Le Treut T, Costello RT: Hematological malignancies escape from NK cell innate immune surveillance: mechanisms and therapeutic implications. Clin Dev Immunol 2012, 2012:421702.

7. Li P, Morris DL, Willcox BE, Steinle A, Spies T, Strong RK: Complex structure of the activating immunoreceptor NKG2D and its MHC class I-like ligand MICA. Nat Immunol 2001, 2:443-451.

8. Cedile O, Popa N, Pollet-Villard F, Garmy N, Ibrahim EC, Boucraut J: The NKG2D ligands RAE-1delta and RAE-1epsilon differ with respect to their receptor affinity, expression profiles and transcriptional regulation. PLoS One 2010, 5:e13466.

9. Lanier $L L: A$ renaissance for the tumor immunosurveillance hypothesis. Nat Med 2001, 7:1178-1180.
10. Diefenbach $A$, Jensen $E R$, Jamieson $A M$, Raulet DH: Rae1 and H60 ligands of the NKG2D receptor stimulate tumour immunity. Nature 2001, 413:165-171.

11. Dou J, Hong X, Zhao F, Wang J, Chen J, Chen G: Investigation of GM-CSF immune accessory effects in tumor-bearing mice by direct gene immunization. Immunol Invest 2006, 35:227-237.

12. Zhao F, Dou J, Wang J, Chu L, Tang Q, Wang Y, Li Y, Cao M, Hu W, Hu K, et al: Investigation on the anti-tumor efficacy by expression of GPIanchored mlL-21 on the surface of B16F10 cells in C57BL/6 mice. Immunobiology 2010, 215:89-100.

13. Cheng M, Li Q, Wan T, Hong X, Chen H, He B, Cheng Z, Xu H, Ye T, Zha B, et al: Synthesis and efficient hepatocyte targeting of galactosylated chitosan as a gene carrier in vitro and in vivo. J Biomed Mater Res B Appl Biomater 2011, 99:70-80.

14. Pan XC, Li L, Mao JJ, Yao W, Zheng JN, Liu M, Fu JJ: Synergistic effects of soluble PD-1 and IL-21 on antitumor immunity against H22 murine hepatocellular carcinoma. Oncol Lett 2013, 5:90-96.

15. Routes JM, Ryan S, Morris K, Takaki R, Cerwenka A, Lanier LL: Adenovirus serotype 5 E1A sensitizes tumor cells to NKG2D-dependent NK cell lysis and tumor rejection. J Exp Med 2005, 202:1477-1482.

16. Yigit R, Massuger LF, Figdor CG, Torensma R: Ovarian cancer creates a suppressive microenvironment to escape immune elimination. Gynecol Oncol 2010, 117:366-372

17. Nagao M, Nakajima Y, Hisanaga M, Kayagaki N, Kanehiro H, Aomatsu Y, Ko S, Yagita H, Yamada T, Okumura K, Nakano H: The alteration of Fas receptor and ligand system in hepatocellular carcinomas: how do hepatoma cells escape from the host immune surveillance in vivo? Hepatology 1999, 30:413-421.

18. Siddle HV, Kreiss A, Tovar C, Yuen CK, Cheng Y, Belov K, Swift K, Pearse AM, Hamede $\mathrm{R}$, Jones $M E$, et al: Reversible epigenetic down-regulation of MHC molecules by devil facial tumour disease illustrates immune escape by a contagious cancer. Proc Natl Acad Sci USA 2013, 110:5103-5108.

19. Li MS, Ma QL, Chen Q, Liu XH, Li PF, Du GG, Li G: Alpha-fetoprotein triggers hepatoma cells escaping from immune surveillance through altering the expression of Fas/FasL and tumor necrosis factor related apoptosis-inducing ligand and its receptor of lymphocytes and liver cancer cells. World I Gastroenterol 2005, 11:2564-2569.

20. Zhang P, Wang J, Wang D, Wang H, Shan F, Chen L, Hou Y, Wang E, Lu CL: Dendritic cell vaccine modified by Ag85A gene enhances anti-tumor immunity against bladder cancer. Int Immunopharmacol 2012, 14:252-260.

21. Onishi H, Koya N, Kiyota A, Tanaka H, Umebayashi M, Katano M, Morisaki T: A new method for rapid cytotoxic T-lymphocyte induction using a multiple cytokine cocktail. Anticancer Res 2012, 32:2385-2390.

22. Baba T, Iwasaki S, Maruoka T, Suzuki A, Tomaru U, Ikeda H, Yoshiki T, Kasahara M, Ishizu A: Rat CD4+ CD8+ macrophages kill tumor cells through an NKG2D- and granzyme/perforin-dependent mechanism. J Immunol 2008, 180:2999-3006.

23. Barber A, Sentman CL: Chimeric NKG2D T cells require both T cell- and host-derived cytokine secretion and perforin expression to increase tumor antigen presentation and systemic immunity. J Immunol 2009, 183:2365-2372.

24. Pellegrini M, Mak TW, Ohashi PS: Fighting cancers from within: augmenting tumor immunity with cytokine therapy. Trends Pharmacol Sci 2010, 31:356-363.

25. Maeda M, Yanagawa Y, Iwabuchi K, Minami K, Nakamaru Y, Takagi D, Fukuda S, Onoe K: IL-21 enhances dendritic cell ability to induce interferon-gamma production by natural killer T cells. Immunobiology 2007, 212:537-547.

26. Penafuerte C, Bautista-Lopez N, Boulassel MR, Routy JP, Galipeau J: The human ortholog of granulocyte macrophage colony-stimulating factor and interleukin-2 fusion protein induces potent ex vivo natural killer cell activation and maturation. Cancer Res 2009, 69:9020-9028.

27. Ramstead AG, Schepetkin IA, Quinn MT, Jutila MA: Oenothein B, a cyclic dimeric ellagitannin isolated from Epilobium angustifolium, enhances IFNgamma production by lymphocytes. PLoS One 2012, 7:e50546.

28. Ramstead AG, Jutila MA: Complex role of gammadelta T-cell-derived cytokines and growth factors in cancer. J Interferon Cytokine Res 2012, 32:563-569.

29. Zanon RG, Cartarozzi LP, Victorio SC, Moraes JC, Morari J, Velloso LA, Oliveira AL: Interferon (IFN) beta treatment induces major histocompatibility complex (MHC) class I expression in the spinal cord and enhances axonal growth 
and motor function recovery following sciatic nerve crush in mice. Neuropathol Appl Neurobiol 2010, 36:515-534.

30. Zhao MF, Qu XJ, Qu JL, Jiang YH, Zhang Y, Hou KZ, Deng H, Liu YP: The role of $\mathrm{E} 3$ ubiquitin ligase $\mathrm{Cbl}$ proteins in interleukin-2-induced Jurkat T-cell activation. Biomed Res Int 2013, 2013:430861.

31. Xu X, Rao GS, Groh V, Spies T, Gattuso P, Kaufman HL, Plate J, Prinz RA: Major histocompatibility complex class I-related chain A/B (MICA/B) expression in tumor tissue and serum of pancreatic cancer: role of uric acid accumulation in gemcitabine-induced MICA/B expression. BMC Cancer 2011, 11:194.

32. Whiteside $T L$ : What are regulatory $T$ cells (Treg) regulating in cancer and why? Semin Cancer Biol 2012, 22:327-334.

33. Song $\mathrm{KD}$, Hwang $\mathrm{S}$, Yun $\mathrm{CH}: \mathrm{T}$ cell receptor signaling that regulates the development of intrathymic natural regulatory T cells. Immune Netw 2011, 11:336-341.

34. Bergmann C, Wild CA, Narwan M, Lotfi R, Lang S, Brandau S: Human tumor-induced and naturally occurring Treg cells differentially affect NK cells activated by either IL-2 or target cells. Eur J Immunol 2011, 41:3564-3573.

35. Han WG, Schuurhuis DH, Fu N, Camps M, van Duivenvoorde LM, Louis-Plence P, Franken KL, Huizinga TW, Melief CJ, Toes RE, Ossendorp F: DC-induced CD8(+) T-cell response is inhibited by MHC class II-dependent DX5(+)CD4(+) Treg. Eur J Immunol 2009, 39:1765-1773.

36. Pallikkuth $\mathrm{S}$, Rogers $\mathrm{K}$, Villinger $F$, Dosterii M, Vaccari M, Franchini $G$, Pahwa $R$, Pahwa S: Interleukin-21 administration to rhesus macaques chronically infected with simian immunodeficiency virus increases cytotoxic effector molecules in T cells and NK cells and enhances B cell function without increasing immune activation or viral replication. Vaccine 2011, 29:9229-9238.

37. Park YK, Shin DJ, Cho D, Kim SK, Lee JJ, Shin MG, Ryang DW, Lee JS, Park MH, Yoon JH, Jegal YJ: Interleukin-21 increases direct cytotoxicity and IFN-gamma production of ex vivo expanded NK cells towards breast cancer cells. Anticancer Res 2012, 32:839-846.

38. Tian Y, Yuan C, Ma D, Zhang Y, Liu Y, Zhang W, Hou F, Cui B: IL-21 and IL-12 inhibit differentiation of Treg and $\mathrm{TH} 17$ cells and enhance cytotoxicity of peripheral blood mononuclear cells in patients with cervical cancer. Int $J$ Gynecol Cancer 2011, 21:1672-1678.

doi:10.1186/1476-4598-12-166

Cite this article as: Cheng et al:: Activation of cellular immunity and marked inhibition of liver cancer in a mouse model following gene therapy and tumor expression of GM-SCF, IL-21, and Rae-1. Molecular Cancer 2013 12:166.

\section{Submit your next manuscript to BioMed Central and take full advantage of:}

- Convenient online submission

- Thorough peer review

- No space constraints or color figure charges

- Immediate publication on acceptance

- Inclusion in PubMed, CAS, Scopus and Google Scholar

- Research which is freely available for redistribution 